\title{
Safety analysis of live working operators under zero potential
}

\author{
Yang $\mathrm{Qi}^{1,2}$, Wang Zhenyu ${ }^{1,2^{*}}$, Zhu Liang ${ }^{1,2}$, Zou Dehua ${ }^{1,2}$, Guo Hao $^{1,2}$ \\ ${ }^{1}$ Hunan transmission Maintenance Company,Changsha 410100, China \\ ${ }^{2}$ Live Inspection and Intelligent Operation Technology State Grid Corporation Laboratory, Changsha 410100, China.
}

\begin{abstract}
With the application of the live working method of the zero phase potential of the working phase more and more widely, the safety of the live working operators is urgently needed for research. Considering the influence of electric shock time and frequency on the allowable current of the human body, the safe current is analyzed during live operation, and it is concluded that in the frequency range of $50 \sim 60 \mathrm{~Hz}$, the current below $50 \mathrm{~mA}$ can basically guarantee that it will not die after electric shock. In the three scenarios where the insulator maintenance personnel accidentally touch the ground, the grounding wire shocks the electric shock and the charged electric shock of the tower, the human body electric shock is further analyzed. Finally, based on the CDEGS, the model of the human body contacting the grounding conductor is established. The simulation verifies the influence of the allowable current on the time and frequency of the human body withstand current under the zero potential state through the contact voltage diagram and the danger degree diagram.
\end{abstract}

\section{Introduction}

With the rapid development of China's power grid and the continuous improvement of power supply reliability requirements, the corresponding live working technology has made new developments and breakthroughs[1]. The live working of the distribution network is of great concern to the operators of live working, but the safe current is affected by many aspects during live working[2]. Therefore, research on the safety of live operators is getting more and more attention and attention.

In order to analyze the safety of live operators, in recent years, the research on live working has been rapidly developed. In the current study, there are two main ways of non-powered live charging:(1) Working directly on live lines or equipment. Reference [3] divided live working into ground potential operation method, intermediate potential operation method, and equipotential operation method; The trial range of live working methods has been studied in [4]; In [5], the safety spacing and operation mode of live working were studied, and the actual operation simulation test of the live working of the insulated bucket car was carried out. (2) Continuous power supply to users by means of bypass or mobile power. Reference [6] proved that the charging operation under bypass conditions is safe; Reference [7] introduced the method of implementing protective grounding for bypass flexible cable in integrated unpowered operation of $10 \mathrm{kV}$ distribution network; Three mobile power operation methods for mobile power generation vehicles, load transfer vehicles and EPS emergency power supply vehicles were introduced in [8]. The prior art has certain security risks, so the need for personal safety cannot be met, and the influence of the measurement distance error on the working phase is also neglected.

In view of this, this paper considers the influence of electric shock time and frequency on the allowable current of the human body, and analyzes the safe current during live working. In the three scenarios where the insulator maintenance personnel accidentally touched the ground, the grounding wire shocked electric shock and the charged body of the tower and the like, the human body electric shock was further analyzed. Finally, based on the CDEGS, the model of human body and grounding conductor is established. The simulation verifies the influence of the allowable current on the time and frequency of the human body withstand current under the zero potential state through the contact voltage diagram and the danger degree diagram.

\section{Safe current analysis}

\subsection{The effect of electric shock time on the allowable current of the human body}

Considering the influence of the current flowing through the human body on personal safety, if the current is above $80 \mathrm{~mA}$, it may pose a threat to the human body in a very short time. If the current is extremely small, the human body can withstand a considerable period of time without the irreversible fatal danger. For the relationship between time and current and personal safety, formula (1) is used to calculate the relationship between the current allowed to pass through the human body and the duration. 


$$
I_{K} t=K_{S}
$$

Where $I_{K}$ is the effective value of the current through the human body, the unit is $\mathrm{mA}$; $t$ is the duration of the shock, the unit is s; the coefficient $K_{S}$ is a constant. It is appropriate to take $50 \mathrm{~mA}$ through the effective value of the human body. Equation (1) can be characterized by curve A of FIG. If the curve A is used as the limit, the upper right side is the danger range. For example, a current of $100 \mathrm{~mA}$ flowing through the human body is extremely dangerous, but if it can be removed within $0.1 \mathrm{~s}$, it does not necessarily cause injury. In addition, when the current through the human body is below $50 \mathrm{~mA}$, the safety margin in curve $\mathrm{A}$ is independent of time. $I_{K} t=30 \mathrm{~mA}$ corresponds to curve $\mathrm{B}$, using a safety factor of 1.67 .

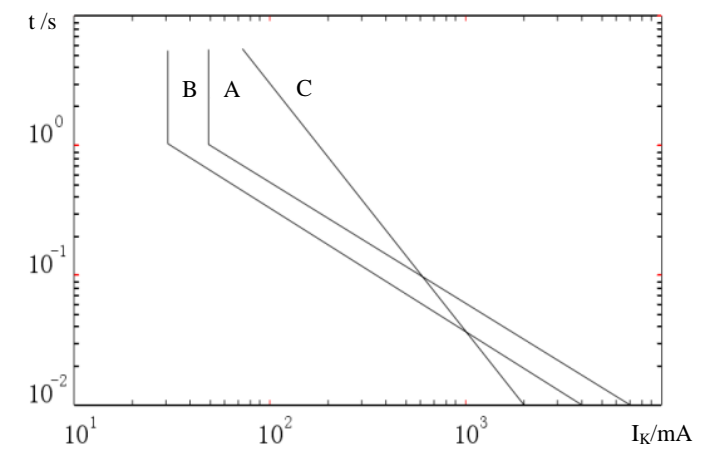

Figure 1. The curve of the allowable limit current and the tolerance time of the human body

According to the formula mentioned above, it is calculated that if the duration is very short, the human body can withstand a large current without causing a current value of cardiac fibrillation:

$$
I^{2}{ }_{K} t=K
$$

Where the unit of $I_{K}$ is $\mathrm{A}$; the coefficient $\mathrm{K}$ is the energy coefficient related to the body weight. Figure 2 shows the relationship between the current value of fibrillation and body weight in the heart within $3 \mathrm{~s}$. This curve is valid for $99.5 \%$ of people. This curve is valid for $99.5 \%$ of people. From the maximum ventricular non-chattering current curve in the figure, the energy coefficient $K 50=0.0135$ and $K 70=0.0247$ for people weighing $50 \mathrm{~kg}$ and $70 \mathrm{~kg}$ are obtained. Therefore, the safe current $I_{K 50}$ of a human body with a body weight of $50 \mathrm{~kg}$ can be obtained as follows:

$$
I_{K 50}=0.116 / \sqrt{t}
$$

Substituting the data into equation (3), the corresponding allowable current value is $116 \mathrm{~mA}$ for a duration of $1 \mathrm{~s}, 367 \mathrm{~mA}$ for $0.1 \mathrm{~s}$ (6 cycles), and $519 \mathrm{~mA}$ for $0.05 \mathrm{~s}$. The safe current of a human body weighing $70 \mathrm{~kg}$ is:

$$
I_{K 70}=0.157 / \sqrt{t}
$$

Convert the above calculation formula into a graph, as shown in the following three curves in Figure 2, that is, the human body allows safe current limits in general.

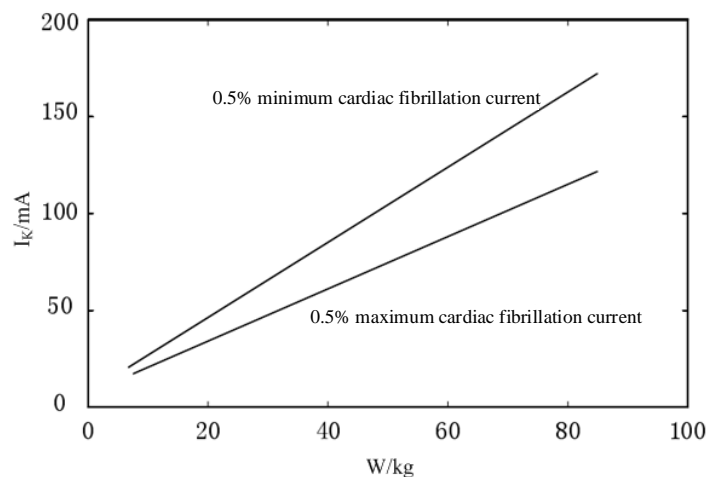

Figure 2. Relationship between current value and body weight of fibrillation in the heart within $3 \mathrm{~s}$

If the duration is set to $3 \mathrm{~s}$, the equation (4) can be obtained from the relevant experiment. Obviously, if a certain current value that the human body may bear, it may be dangerous if the electric shock is sustained for a period of time. $100 \mathrm{~mA}$ was used as the ventricular fibrillation threshold without clearly specifying the shock time. However, this does not include long-term electric shocks, nor does it rule out the possibility of suffocation caused by contraction of the chest muscles. Therefore, he believes that the safety threshold is usually $25 \mathrm{~mA}$ if the electric shock voltage lasts for a few minutes or longer and there is no rapid ambulance.

In response to this problem, the IEC obtained the relationship between the power frequency current and the electric shock time leading to ventricular fibrillation, as shown in Figure 3. The area from the right side of the curve C1 (area-4) is the area where ventricular fibrillation occurs, and an electrocution dead zone may occur. Among them, curve $\mathrm{C} 1$ represents ventricular fibrillation in all populations, curve $\mathrm{C} 2$ represents ventricular fibrillation in 5\%, and $\mathrm{C} 3$ represents ventricular fibrillation in $50 \%$ of people. It is particularly noted that the human body current above the $\mathrm{C} 2$ curve (above the electric shock time of $5000 \mathrm{~ms}$ or more) is 50 $\mathrm{mA}$, which is the ventricular fibrillation threshold of the human body selected in general, in other words, the human current of $50 \mathrm{~mA}$ is a fatal dangerous current. . From another point of view, only $5 \%$ of people under the action of $50 \mathrm{~mA}$ current may produce ventricular fibrillation, and $95 \%$ of people do not produce ventricular fibrillation. It is safe. From the principle of general selection of safety limits, the ventricle The fibrillation threshold of $50 \mathrm{~mA}$ can be regarded as the current safety threshold of the human body. It is not an absolute safety limit, however, if an absolutely safe current is chosen as the current safety threshold, this value may be too small to be of application value. 


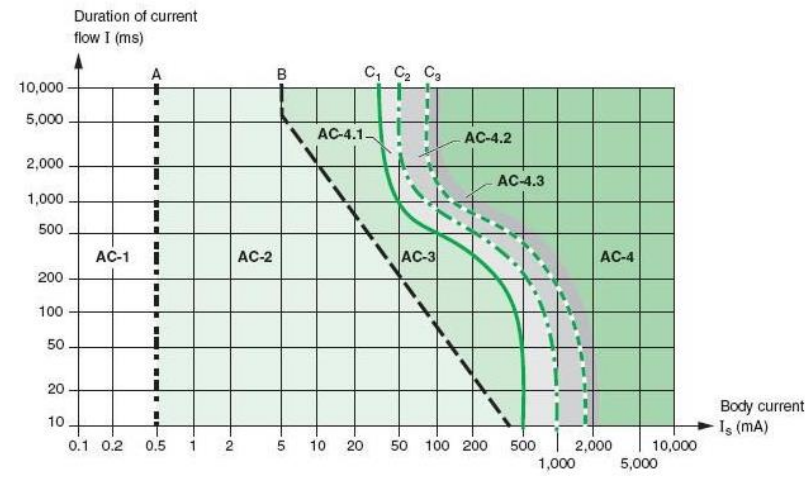

Figure 3. Current threshold curve of human heart fibrillation

Nevertheless, when considering the impact of the actual distribution network protection device on personal safety, it is necessary to consider the relationship between the grounding current and the current flowing through the human body. Because the environment of the distribution network varies widely, the direct current can not be directly used to limit the distribution. The processing accuracy of the network fault processing technology, but combined with domestic and foreign experiments and research can basically be considered, $50 \mathrm{~mA}$ is the general fibrillation threshold, that is, the current below $50 \mathrm{~mA}$, can basically guarantee that it will not die after electric shock.

\subsection{The effect of frequency on the allowable current of the human body}

At present, the research on electric shock accidents at home and abroad mainly focuses on the power frequency range of $50 \sim 60 \mathrm{~Hz}$. Many research data show that the human body is most seriously damaged by the current frequency of $50 \mathrm{~Hz}$ or $60 \mathrm{~Hz}$. The human body's tolerance to power frequency current is very low. About $100 \mathrm{~mA}$ current acts on the human body, which will cause fatal consequences. Below or above this frequency, the damage will be reduced. For the human body, the minimum inrush current that can be felt is 40 to $90 \mathrm{~mA}$, which is much higher than the AC sensation current of 1 $\mathrm{mA}$ and the DC sensation current of $5 \mathrm{~mA}$. Under the action of lightning current, the human body may withstand a few hundred amperes of current amplitude. However, in the case of DC and inrush current, the risk of inrush current is greater, because the lightning current amplitude can reach several thousand amperes under normal conditions. Figure 4 shows the effect of frequency on the current threshold of the human heart fibrillation. When the current passes through the human torso, the current action time is at least 1 cardiac cycle. The frequency factor in the figure also refers to the human heart fiber caused by high frequency. The ratio of the current threshold of the tremor to the corresponding value of the power frequency.

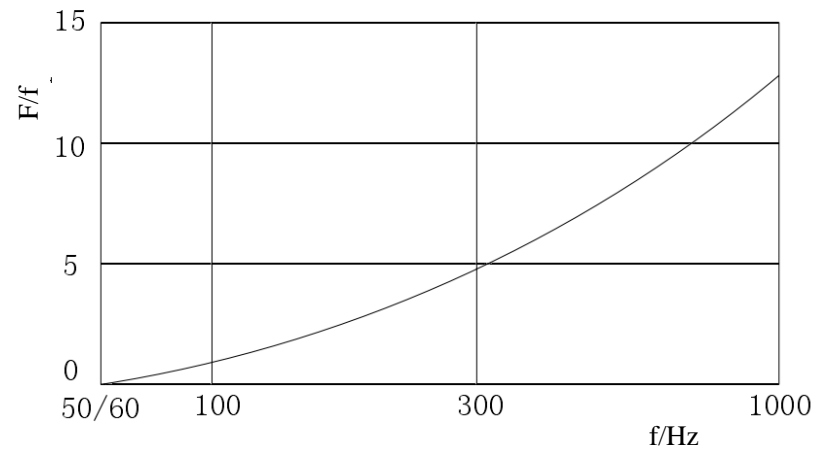

Figure 4. Effect of frequency on the current threshold of human heart fibrillation

\section{Analysis of personal electric shock scene}

\subsection{Insulator maintenance staff accidentally hit the ground}

When the system staff inspects the insulator, the line should be open and de-energized, but sometimes the operator may be mistakenly closed due to the negligence of the staff, causing the line to be charged. The twohanded maintenance personnel will discharge to the ground through the crane. The electric shock diagram is shown in Figure 5.

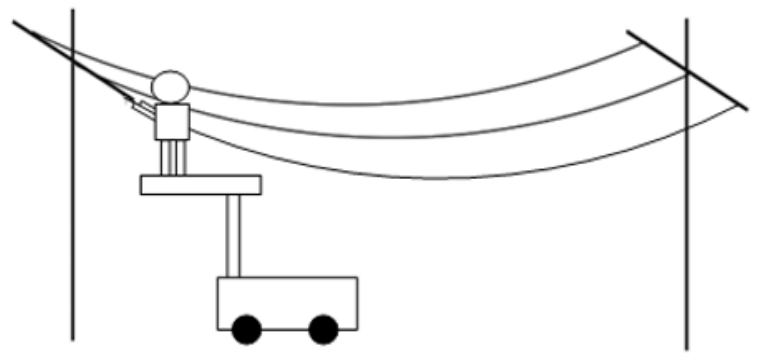

Figure 5. Insulator maintenance staff accidentally hit the ground

Active touch of live conductors on the tower: The grid staff for the purpose of line change maintenance touched the unintentionally charged conductor.

\subsection{Ground wire electric shock}

Due to weather or human factors, the live conductors are directly grounded or grounded through leaves, etc., ground faults may not be disposed of for a long time, and electric shocks may occur after pedestrians accidentally touch. On the other hand, for some high-resistance ground faults, or disconnected ground faults, there may be no grounding alarms in the station, resulting in grounding not being discovered. When people pass the wires, due to human hands and feet (contact electric shock) or double The electric shock between the feet (stepping electric shock) is caused by the voltage difference. The electric shock diagram is shown in Figure 6. 


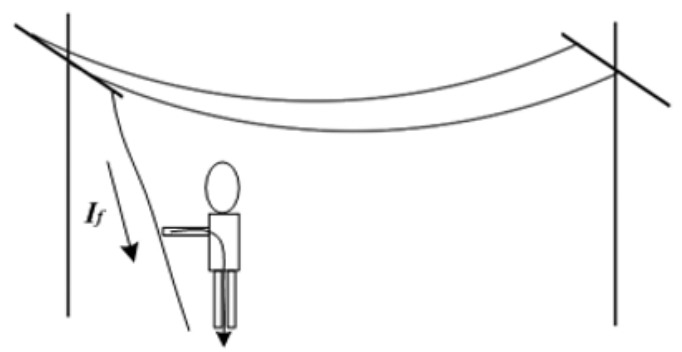

(a) Contact electric shock

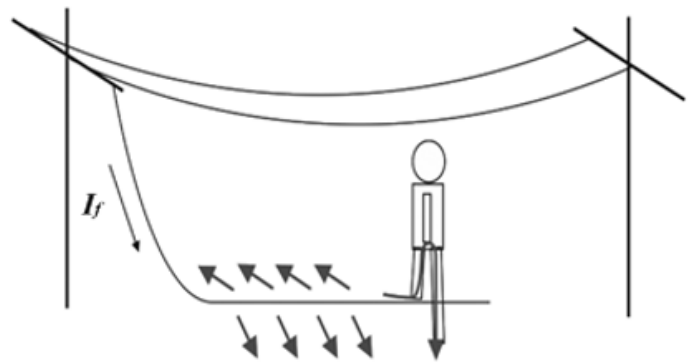

(b) Stepping electric shock

Figure 6. Contact electric shock and strid electric shock caused by grounding wire

\subsection{Charged body such as tower}

A single-phase earth fault or a two-phase earth fault is the most common form of tower charging. Ground currents flowing through the tower may cause personal contact shocks or striding shocks. The electric shock diagram is shown in Figure 7.

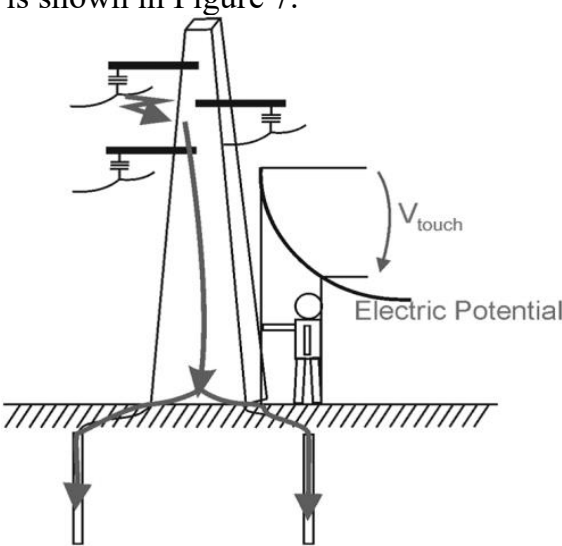

Figure 7. Charged body such as tower

The wire breaks through the human body to the ground: the probability of occurrence of such an event occurs when the wire is dropped directly to the person or the person is walking to the suspended wire. However, it will cause serious harm to the human body after the occurrence. Moreover, since the human body is the only conductor that discharges the wire to the ground, the ground fault current is much more harmful to the human body than in other scenarios. The electric shock diagram is shown in Figure 8.

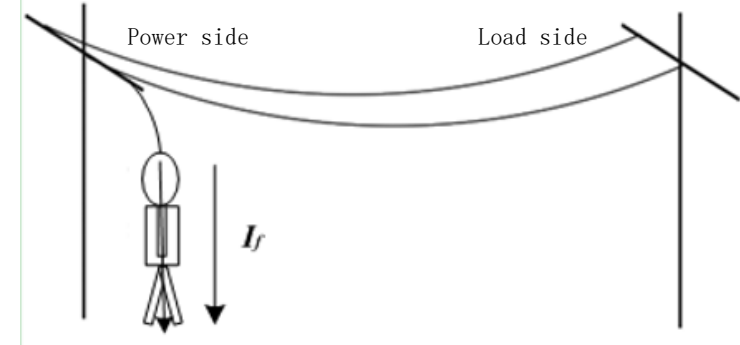

(a) Power supply disconnection ground

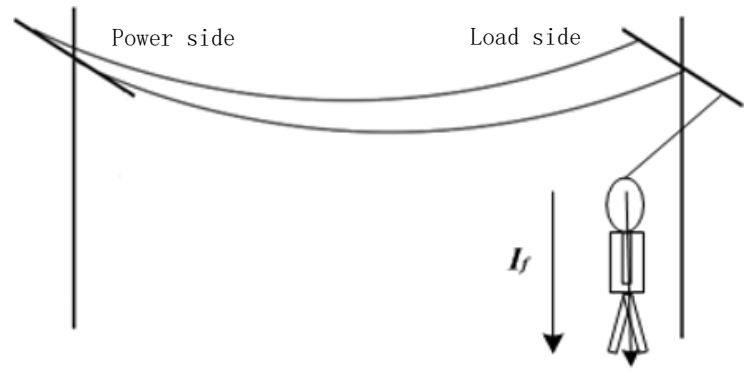

(b) Load side disconnection grounding

Figure 8. Schematic diagram of electric shock due to human body grounding

\section{Verification of Simulation}

After the human body comes into contact with the grounding wire, the grounding resistance is converted from $R_{f}$ to $R_{f}^{\prime}$ due to the body resistance, as shown in Figure 9.

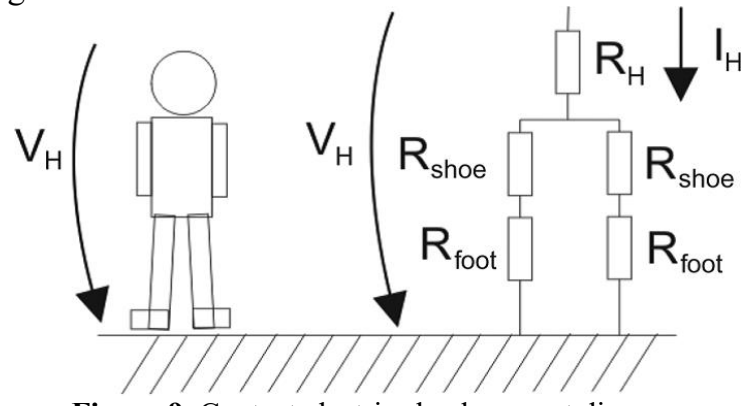

Figure 9. Contact electric shock current diagram

At this time there are:

$$
\left\{\begin{array}{l}
R_{f}^{\prime}=\frac{R_{f} \cdot R_{H}}{R_{f}+R_{H}} \\
U_{\text {touch }}=U_{\mathrm{C}}^{\prime}=\frac{-R_{f}^{\prime} E_{C}\left(3 Y_{0}-Y_{L}\right)}{R_{f}^{\prime}\left(3 Y_{0}-Y_{L}\right)+1}
\end{array}\right.
$$

The contact voltage that the human body bears and the location of the contact point determine the amount of current flowing through the human body, which determines whether the human body is safe or not. The specific value of the current $I_{H}$ flowing through the human body also depends on the human body resistivity, shoe resistivity, foot-to-ground resistivity, etc., as shown in equation (6).

$$
V_{\text {touch }}=\left[R_{H}+0.5\left(R_{\text {foot }}+R_{\text {shoe }}\right)\right] I_{H}
$$

Taking a $10 \mathrm{kV}$ medium voltage distribution line as an example, the arc suppression coil inductance value is $L=0.25 \mathrm{H}$, and the phase parameters of each phase are 
$C_{\mathrm{A}}=10.21 \mu \mathrm{F} \quad, \quad r_{\mathrm{A}}=10.67 \mathrm{k} \Omega \quad, \quad C_{\mathrm{B}}=9.64 \mu \mathrm{F} ，$ $r_{\mathrm{B}}=10.65 \mathrm{k} \Omega, C_{\mathrm{C}}=10.81 \mu \mathrm{F}, r_{\mathrm{C}}=10.56 \mathrm{k} \Omega$.

Then the total capacitance of the grid to the ground $C_{\Sigma}=30.66 \mu \mathrm{F}$, the total conductance $G_{\Sigma}=2.82 \times 10^{-4} \mathrm{~S}$, $\dot{k}_{\mathrm{A}}=-3.18 \times 10^{-4}-\mathrm{j} 1.35 \times 10^{-6}$ to the ground, the human body resistance is $1000 \mathrm{ohms}$, the total grounding impedance is the parallel connection between the human body resistance and the grounding resistance, and the fault voltage $U_{C}$ and current $I_{f}$ under different grounding resistances can be obtained as shown in Table 1. Shown.

Table 1. 10kV fault current and voltage under different grounding resistances

\begin{tabular}{cccc}
\hline $\begin{array}{c}\text { Grounding } \\
\text { resistance } / \Omega\end{array}$ & $\begin{array}{c}\text { Grounding total } \\
\text { resistance } / \Omega\end{array}$ & $\begin{array}{c}\text { Fault } \\
\text { current /A }\end{array}$ & $\begin{array}{c}\text { Fault } \\
\text { voltage } / \mathrm{V}\end{array}$ \\
\hline 8 & 7.95 & 95.0 & 760 \\
25 & 24.59 & 26.3 & 640.0 \\
200 & 176 & 21.0 & 4150.0 \\
500 & 375 & 11.2 & 5450.0 \\
2000 & 857 & 3.96 & 8080.0 \\
\hline
\end{tabular}

Verification was performed using the MALZ module of CDEGS. Taking a $10 \mathrm{kV}$ distribution line as an example, the ground fault current is $10 \mathrm{~A}, 50 \mathrm{~A}$, and $100 \mathrm{~A}$, respectively.

In this case, the grounding body is a wire, and the injection current is the grounding current. The diffusion of the grounding current is shown in Fig. 10.
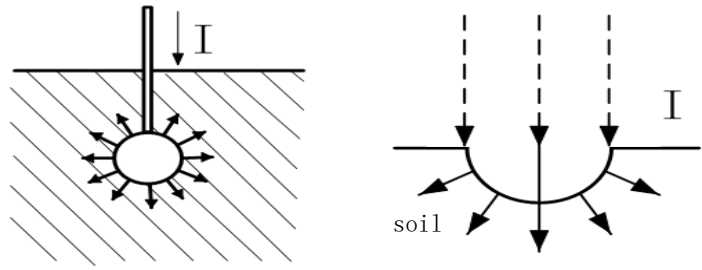

Figure 10. Schematic diagram of diffusion in soil with ground current

The current flows through the soil and forms a ground potential on the surface of the soil. The soil composition and soil water content are closely related to the conductivity of the earth. Therefore, the earth's conductivity is not constant, and as the soil goes deeper, its conductivity will increase. According to the relevant research, the three-layer soil hemispherical earth model established in the paper has different resistivity. The surface soil thickness is $1 \mathrm{~m}$, the resistivity is $300 \Omega / \mathrm{m}$, the second layer thickness is $3 \mathrm{~m}$, and the resistivity is $100 \Omega / \mathrm{m}$. The lowest soil resistivity is $50 \Omega / \mathrm{m}$; the radius of the earth is set to $40 \mathrm{~m}$, because the potential has dropped to zero, $40 \mathrm{~m}$ away from the grounding point. At the same time, a cylindrical grounding body model was established, and the contact electric shock simulation caused by the grounding wire of the soil model was carried out by using the MALZ module of CDEGS.

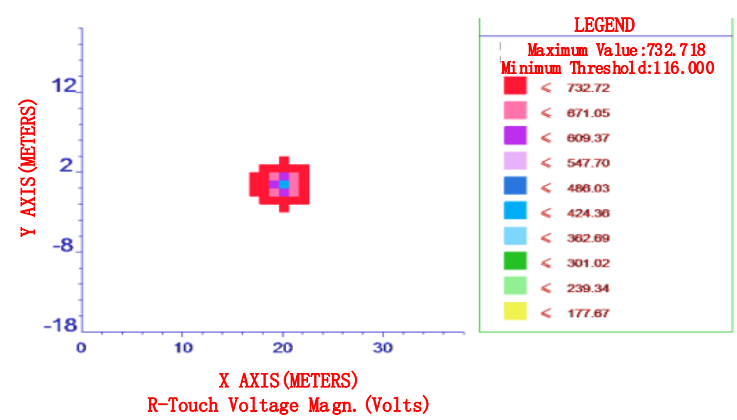

Figure 11. Schematic diagram of the danger of contact voltage of distribution network

In the case where the total grounding resistance is 10 ohms or less, the fault ground current is set to $100 \mathrm{~A}$, then the contact voltage that can be withstood when the person approaches the grounding conductor is as shown in Fig. 11, and each line on the way represents an observation of the observation surface. Line; of course, considering that the contact shock will inevitably occur within a certain range from the grounding conductor, so the fault distance must be required, as shown in Figure 11 is schematic diagram of the danger of contact voltage of distribution network.

\section{Conclusion}

1. Current below $50 \mathrm{~mA}$ can basically guarantee that it will not die after electric shock;

2. The human body is most seriously damaged by the current frequency of $50 \mathrm{~Hz}$ or $60 \mathrm{~Hz}$. The human body's tolerance to the power frequency current is very low. About $100 \mathrm{~mA}$ current acts on the human body, which will cause fatal consequences;

3. Based on the CDEGS, the model of the contact between the human body and the grounding conductor is established. The simulation verifies the influence of the allowable current on the time and frequency of the human body withstand current under the zero potential state through the contact voltage diagram and the danger degree diagram.

\section{References}

1. Hadi Suyono, Rini Nur Hasanah, Eka Putra Widyananda, Power system optimization of static var compensator using novel global harmony search method[C], International Journal of Electrical and Electronic Engineering \& Telecommunications, 2019, 8(1): 26-32.

2. Mahya Aghaee, Elnaz Ghanbaryan. Economic dispatch in power systems using simulated annealing-based-clonal selection optimization approach[C], International Journal of Electrical and Electronic Engineering \& Telecommunications, 2016, 5(3): 25-34.

3. Carreira A J, Cherney E A, Christman R A, et al. Guidelines for Establishing Diagnostic Procedures 
for Live-Line Working of Nonceramic Insulators[J]. IEEE Transactions on Power Delivery, 2014, 29(1):126-130.

4. Wang L, Zhang $\mathrm{Q}, \mathrm{Hu} \mathrm{J}$, et al. Research on Complex Gap Discharge Model of Live Working on EHV and UHV High-Voltage Transmission Lines[J]. Canadian Journal of Electrical \& Computer Engineering, 2014, 37(1):11-18.

5. Ghassemi M, Farzaneh M. Effects of tower, phase conductors and shield wires on the electrical field around a tower window during live-line work[J]. IEEE Transactions on Dielectrics and Electrical Insulation, 2015, 22(6):3413-3420.
6. Mcdermid W, Swatek D. Experience with dielectric surfaces of FRP tools used in live line work[J]. IEEE Transactions on Dielectrics and Electrical Insulation, 2014, 21(6):2415-2427.

7. LI Tianyou. A review of the development of nonservice interruption working technology in distribution network[J], DISTRIBUTION \& UTILIZATION, 2015, 32(05): 6-10+21.

8. Huang Z L, Zhang Q S, Liu C X, et al. The Application Discussion of Virtual Reality Technology in Power Distribution Network Live Working Training[J]. Applied Mechanics \& Materials, 2013, 278-280:2152-2155. 